\title{
Analysis on the English-translation Errors of Public Signs*
}

\author{
Minghe Guo \\ School of Foreign Languages, Changchun University of Science and Technology, Changchun 130022, China \\ Email: cwkerbao@sina.com
}

\begin{abstract}
With the rapid progress of economy, the intensification of China's reform and opening-up policy, as well as the successful celebration of a number of great global events, China is attracting more attention worldwide and myriad foreign visitors stream into China. An increasing number of public signs are presented in both Chinese and English which are regarded as a symbol of a city's internationalization degree. However, the frequent problems in the translation of public signs degrade China's international status as a major role on the global platform. Mistranslation of public signs is an emergent issue that needs immediate attention.
\end{abstract}

Index Terms-public signs, English translation, functions, mistranslation

\section{INTRODUCTION}

In the past 30 years of the implementation of opening and reform policy, the outside world has witnessed China's great progress in the economic, scientific, technological and cultural fields. The rapid elevation in the economic and international status of china results in a steady influx of foreigners to take participate in various activities in China, such as the $6^{\text {th }}$ Asian Winter Games in our city Changchun, 29th Olympic Games held in Beijing, the World Exposition in Shanghai, etc. With more people from overseas travelling, working or studying in China, the significance of providing English public signs in big cities of China has become increasingly prominent. Bilingual public signs are not uncommon in the public places like streets, stations, parks and tourist attractions. Public signs are mainly words with or without pictures which are used in public places to provide necessary information and convenience. The basic functions of them are directing, prompting, restricting and compelling. These signs are a great help for the foreigners who cannot understand Chinese to get the information they need. However, the existing English translations of public signs in China are far from perfect. Numerous non-standard translations or errors in translation had been noticed and they will inevitably cause the great inconvenience and trouble for foreigners visiting China and most seriously make an awful impression on them. The translation of public signs from Chinese to English, as a special translation mode, has drawn increasing attention in translation field in recent years. It is quite necessary to make a probe into the existing problems and find errors before we can find effective solutions.

\section{Functions OF Public SignS}

Public signs are functional, functioning differently due to different occasions and situations. Classifications of them can help us find out the common features they have. Prof. Lv Hefa proposed the four major functions of public signs in China: directing, prompting, restricting and compelling. (Lv Hefa, 2004) Later, together with Dai zongxian, Lv Hefa provided the classification of public signs of 2 kinds: static and dynamic indication. They pointed out that the static indication performs the directing function while the prompting, restricting or compelling function is shown by the dynamic indication. (Dai Zongxian, Lv Hefa, 2005)

\section{A. Directing}

Public signs bear the function of directing. Directing is to provide detailed information or certain service for people which has no restrictive or compulsory meanings. Directing aims at indicating the content of the service rather than forbidding or requiring people to perform any action. In many situations, it simply denotes what kind of service is being offered, what or where it is. Examples are as follows:

ENTRANCE (入口)

Business Hours: 9:00-16:00 (营业时间: 9:00-16:00)

Ticket Office (售票处)

Fitting Room (试衣间)

These public signs provide relative information and show what the service or information is, reflecting no attitude towards receptors.

\footnotetext{
* This paper is sponsored by the Fund Project of Social Science of Jilin Province in 2011 with project code of 2011B361
} 


\section{B. Prompting}

Prompting public signs remind people to pay considerable attention to a certain fact before they take any action. They mainly aim at mobilizing people to move and act, serving as a reminder in a warning tone in most situations. For instance:

Caution: Wet Floor (小心地滑)

EXIT Changchun 2 KM (前方出口长春 2 公里)

Occupied (则所有人)

Road under Repair (前方道路维修)

Reserved (预留座位)

\section{Restricting}

Restricting public signs constrain the behaviors or actions of people concerned. These words are mostly simple and direct or even comparatively harsh but they would not make people feel rude or impolite with proper language. Take the following signs for example:

Stand in Line (自觉排队)

Keep Right (靠右驾驶)

Staff Only (员工通道)

Admission by Ticket Only (凭票入场)

Usually these signs that bear this function put demands and restrictions on the relevant addressees who are expected to obey public rules.

\section{Compelling}

Compelling public signs demand the public to do something or forbid them to do something. The choice of words is usually brief and compelling without any possibility for consultation and compromise. The sentences are often imperative with negative words like "No", "Do not", "Forbidden", etc. For example:

No photographing. (禁止拍照)

No Littering. (请勿乱扔杂物)

Do not touch. (请勿触摸)

Object from the observation deck is strictly prohibited. (严禁从看台投掷物品)

Construction Site Keep Out (施工现场禁止入内)

Typically these signs use warnings or showing forces to make sure that the information can be accepted and the rules can be obeyed.

\section{ANALYSIS ON ERRors IN THE TRANSLATION OF PUBLIC SignS}

Nord Christiane, a very famous German theorist and a representative of the German functional approach of translation, defines translation errors in this way: If the purpose of a translation is to achieve a particular function for the target addressee, anything that obstructs the achievement of this purpose is a translation error. (Nord.2001:74)

Standard English version of public signs that may perform intended functions should at least meet the following basic specifications: correct spelling, brief and concise language style, choice of appropriate words, use of frequent words and the consideration of cultural differences.

Yet, if we look carefully when walking along the streets in the city we live, when we are in stores, parks, hotels etc., it's not difficult to find many problematic translations of public signs in many public places. These mistranslated public signs are just extremely embarrassing when a foreigner encounters them. An overseas student in my university once said that when he was preparing for his journey to China, he was advised on one of the major pitfalls of traveling and living in China: The bungled English signs that will confuse, mislead, and frustrate you. These improper English versions of public signs which seem insignificant and neglectable exert great negative impact on the realization of their intended function. "As China opens up to tourism, more and more signs have to be translated into English. But as these hilarious examples prove, something is usually lost in the translation." (Daily Mail (London)) The following part dwells on the leading kinds of translation errors that are most frequently seen.

\section{A. Incomprehensible Chinese PINYIN}

At first glance, some public signs are presented in both Chinese and English, but these "English" signs are meaningless and empty to the foreigners because they are actually Chinese PINYIN. These PINYIN public signs can be seen in many public places, for example:

Ouya Chaoshi Liansuo Jishun Dian (欧亚超市连锁吉顺店)

Changchun Qing Gong Jian Zhu （长春轻工建筑公司）

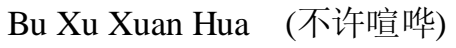

QU YAO KOU (取药口) 
PINYIN translation of public sign in question is the most common and most easily overlooked error in China. This is an extremely lazy and irresponsible translation behavior. Foreigners cannot read Chinese PINYIN, so these public signs are actually not translated for them and of no help to them at all.

\section{B. The Inconsistency in the Translation of Naming}

Sometimes, the translation of some road signs combines Chinese PINYIN translation and English translation together, which makes it more inconvenient and confusing to the foreign visitors. For example, one who walks along the streets in Changchun may find the sign of “西康胡同”"on a building is translated as “Xi Kang Hu Tong”. But on the road sign board, it is translated as "Xikang Alley". It would be easy to imagine that foreign visitors may easily get lost because they may consider "Xi Kang Hu Tong" and "Xikang Alley" to be probably two different places. Other examples like "Chong Qing Lu" and "Chongqing Road", "Jian She Jie" and "Jianshe Street” can be seen everywhere.

\section{Embarrassing Spelling Mistakes}

When you walk in the public places, spelling mistakes of public signs, which involve wrong spelling of a word or missing of one or more letters in a word, can be easily found. Most of the mistakes are due to carelessness and irresponsibility of the translators or the printers. These spelling mistakes will make the original public signs difficulty to understand and leave a negative impression on readers. Following are the examples and explanation:

On the information indicator board in the International Shopping Mall of Changchun, “珠宝” is translated as "Gewelry", which should be "Jewelry" practically. The shopping mall is a five-storey building and there is a information indicator board on each floor of the building, so your guess is right that the spelling mistake is repeated five times.

In another shopping center, the situation is even worse for spelling mistakes can be easily found everywhere. "KTV/ 网吧” is put as “KTV/Internet ban”. This mistake may cause serious misunderstanding to the foreign readers. Originally, this directing public sign is meant to provide information of internet service for people that they can surf Internet if they need. But the translated information indicates the opposite meaning that Internet surfing is not permitted because "ban" means “prohibit” or “forbid". In Chinese, it means“禁止, 禁令”. So the English translation of the sign totally failed to perform its function of directing.

When you see these misspelling public signs, you may be very shocked and even puzzled by the existence of these schoolboy mistakes. But they truthfully exist in the city we live. And probably everyday these wrong spelling signs are spotted by more and more foreigners and at the same time these signs leave a poor impression to foreign visitors on the English proficiency of Chinese people. These low-level errors really do great harm to our city's international image.

\section{Redundancy}

As we have discussed some basic specifications that standardized English version of public signs that may perform intended functions should at least meet, a good public sign should be clear and concise in its form and expression so as to achieve the most effective feedback at the shortest notice. The rule is applicable to both the creation and translation of public signs. English translations of public signs are also public signs in the target language. Any unnecessary and surplus words or expressions may cause deviations in meaning and difficulties in understanding. For example:

Ji Lin Grand Drugstore (吉林大药房)

In the translation of the signboard of the drugstore, the translator, in order to be faithful to the source information, translated “大药房” literally and rigidly as "Grand Drugstore". In Chinese, there are some customary expressions like “大饭店”, “大酒楼”, “大药房, etc., however, in the English translation of these signboards, the words like “big”, "grand" are actually unnecessary and redundant.

Public Toilet (公则)

This is the most typical and commonly seen case of redundancy in the translation of public signs. The proper and different improper way of translating“男/女则所”has been discussed in plenty of articles on translation, but various errors are still visible in many public Places. In this case of mistranslation, the modifier "public" is superfluous.

\section{E. Change or Loss of Information}

The basic purpose of translation lies in the actual realization of the effective communicative value of the source language as well as the successful conveyance of utterance information. In terms of the functions of public signs, directing public signs may depend more on the correction and completion of information to fulfill the goals. However, in the real translation process, the translator may omit certain information of the source language. The reasons vary: some cases of information loss are caused by the translators' carelessness, some others cases may caused by the translator purposely in order to be short and brief in the translation of public signs.

Sometimes, this sort of errors can totally change the message and a distorted intention will emerge. For example:

South Ticket (南售票厅)

North Ticket (北售票厅)

The two signs were found in Changchun Railway Station. According to their Chinese meanings, we can see that the two signs intend to inform people that they can buy tickets in both the two places. Obviously, the translator intends to 
use the word"Ticket" as a noun to express the meaning of a place for passengers to buy "tickets". However, the foreign readers may misunderstand the intended meaning of the translations of the public signs. They may think that they can only buy tickets of trains heading for south or north in the two different ticket halls respectively. The correct translation of “售票厅” should be “ ticket-hall” or "booking hall”.

The following is another example for change or loss of information in translation:

$\begin{array}{lll}1 \mathrm{~F} & \text { cosmetics/clocks \& watches } & \text { (一楼 化妆品/钟表/鞋帽) } \\ 2 \mathrm{~F} & \text { children's products } & \text { (二楼 儿童用品) } \\ 3 \mathrm{~F} & \text { women } & \text { (三楼 女装) }\end{array}$

This directing board locates in the New World Shopping Mall in Changchun. As you can easily find out that the commodities sold on the first floor also include shoes and hats, but in the English version of the sign, the information is missing. The consequence of the information loss in the translation of the directing public sign is that the foreign readers don't know where they can find the shoes or hats they want to buy. Therefore, the translation of the sign fails to function.

If the loss of information caused by carelessness fails to provide complete information to the foreign readers, the loss of information caused by improper omission may confuse them. In the above-mentioned example, the commodities displayed on the 3rd floor should be “women's wear", but in the English translation, “女装” is briefly translated as "women". The literalized information that "women" are displayed and sold in the shopping mall may amaze the foreign visitors. The inappropriate omission of important information in the translation of public signs leads to the vagueness of interpretations and leaves the readers in the maze.

\section{F. Chinglish}

Chinglish, or "Chinese English", refers to spoken or written English language that is influenced by the Chinese language. The term "Chinglish" is commonly applied to ungrammatical or nonsensical English in Chinese contexts, and may have pejorative or deprecating connotations, reflecting the attitudes of those who apply the term. Chinglish offers a humorous and insightful look at the misuses of the English language in Chinese public signs, instruction of products, and advertising. The phenomenon exists commonly in every city in China. That is why there was a big campaign to sort it out in Beijing, just prior to the Olympics Games in 2008.

In order to come up with the idiomatic translation of a public sign, not only does the translator need to think about its form and meaning, but also they should pay attention to the acceptability of the translation. They cannot put them into the way we want and at the same time, they have to avoid word-by-word translation which makes the translation obscure and inconsistent with English linguistic rules or idiomatic expression, which cannot be accepted by English native speakers.

As terrible as this Chinese-English translation is, it is relatively easy to identify most of the translation errors. Take for instance the trouble of translating the direction sign in a hospital:

Among disinfection (消毒间)

“.....间” is used liberally in Chinese to indicate a certain room or place for special purpose, which is usually considered synonymous with "room, place or area" in English. In the translation of the sign, it appears that the translator opted to use a word-for-word translation and put it into two separate words “消毒” (disinfection) and “...... 间”(among) instead of taking into consideration the similar English usage of the words, phrases or idiomatic expressions. In English, there is an idiomatic way to indicate a place or a room for certain movement, like "reading room", "waiting room" and "dining room" etc. So according to idiomatic usage, the acceptable translation should be "sterilizing room".

Therefore, in the translation of signs, we have to learn to think in English instead of Chinese. Even if we may find some similar expressions in Chinese, we should not use them rashly since there is a commonly accepted way to express in English. Now, many local governments in many cities in China are trying diversified measures to reduce or evade Chinglish in the Chinese-English translation of public signs. It really is a good piece of news for the sake of readability of bilingual public signs in China.

\section{G. Grammatical Mistakes}

Whether a translation obeys grammatical rule or not is always the fundamental standard of judging a good one. Therefore, a proper translation should, at least, accord with the grammatical rules or linguistic conventions of the target language. And it is particularly the case in the translation of public signs. Unfortunately, the real situation in our city is that numerous grammatical mistakes in the translation of public signs can be easily found everywhere around us. Most of these grammatical errors are not as noticeable as spelling errors or Chinglish, but they are still disturbing and annoying since they not only show the irresponsible attitude of the translator but also expose the poor proficiency and grasp in the English language of the translator. For example:

Borned outstanding permeated with wise and elegant. (原生非凡, 㔽雅鬼动。)

This advertising public sign was found in a big shopping mall, and it means to advertise a brand of cosmetics. There are glaring grammatical mistakes in the translation of the advertising sign: Firstly, there is no such word as "borned" but "born". "Born" is the past participle of "bear", so the correct usage of the passive voice of "bear" should be "is born", 
"was born" or "were born". For instance, "He was born in South California." Secondly, "with" is a preposition, so it should be followed by nouns or noun phrases, but the translator of the sign obviously neglected the grammatical rule and translated the two words “铨” and “雅” directly into their adjective form "wise” and "elegant”. Actually, they should be put into their noun form "wisdom" and "elegance". The correct translation of the advertising sign which accords with the grammatical rules in English should be "Born outstanding permeated with wisdom and elegance."

\section{H. Inappropriate Choice of Word}

In some cases, a Chinese word may have several counterparts with quite similar meanings in English. Then it is up to the translators to decide on the wording and make their considered choices in the process of translation. The word that is improperly chosen usually causes confusion, ambiguity or misunderstanding.

Sightseeing Ladder (观光梯)

This is a bilingual public sign found in a megastore in Changchun, which attracts many foreign customers every day. The Chinese meaning “梯” has several interpretations in English like "ladder", "elevator", "lift” or "escalator". So in the translation of “观光梯”, what is the key point for the translator is to decide which word to choose to indicate the real object. Then the translator needs to know the specific indication and the fundamental difference between these words. From Wikipedia, a "ladder" is a vertical or inclined set of rungs or steps. There are two types: rigid ladders that can be leaned against a vertical surface such as a wall, and rope ladders that are hung from the top. The vertical members of a rigid ladder are called stringers (US) or stiles (UK). An "elevator" (US) or "lift" (UK) is a type of vertical transport equipment that efficiently moves people or goods between floors (levels, decks) of a building, vessel or other structures. Elevators are generally powered by electric motors that either drive traction cables or counterweight systems like a hoist, or pump hydraulic fluid to raise a cylindrical piston like a jack. An "escalator" is a moving staircase - a conveyor transport device for carrying people between floors of a building. The device consists of a motor-driven chain of individual, linked steps that move up or down on tracks, allowing the step treads to remain horizontal. As we can contrast the real object with these meanings, "ladder" is the wrong translation of “梯” in the sign and the proper choice of the word should be "elevator" or "lift".

\section{Mistranslation on the Cultural Level}

Apart from mistranslations on the linguistic level, translating problems from the cultural perspective also needs attentive study.

Language is universally regarded as a reflection and carrier of culture, varies greatly from nation to nation. Hence, as totally two different languages, English and Chinese present themselves with distinctive cultural features as well as corresponding language styles due to the striking differences of the east and the west. Public signs cannot be denied as one of the main carriers of ethnological culture, and the meaning of the signs should not only implicate the entity but also connote the notion of the culture. Therefore, public sign translation from Chinese to English is not only a bilingual activity, but also a bicultural activity. It is closely related and even confined to the range of culture.

For translators, translation is a complicated and painstaking activity which involves the comparison of the two languages and two cultures, and they sometimes may encounter great cultural barriers and difficulties. Likewise, without intensive understanding of the cultural information connoted in words or concepts, the translator would find it tough or even impossible to accomplish the translation task. Consequently, the mistranslations concerning culture emerge.

Customers are God. (顾客是上帝)

This sign in a small supermarket is a case in point to show the translator's ignorance of western culture. "God" occupies the sacred position in the westerners' mind. So in the eyes of westerners, customers can never be compared to God even though they should be specially respected. "Customers First" can commendably indicate the intended meaning and avoid offending the target readers.

Compared with linguistic mistranslation, mistranslation on the cultural level, to some extent, is more intolerable to target readers. Linguistic mistranslation is usually the consequence of translators' linguistic incompetence. However, translation mistakes on the cultural level may on the one hand make foreigners feel they are offended in terms of their customs, beliefs and faith; on the other hand, some other signs baring characteristics of Chinese culture are translated literally without taking account of the cultural differences, which may cause misunderstanding and barricade the foreigners from understanding Chinese culture.

Spring Transportation arrange extra trains (春运加开列车)

This public sign was found in the railway station in Changchun before the Spring Festival. The word “春运” can never be simply translated as "Spring Transportation" because it is related to a traditional festival in China-the Spring Festival. So “春运” actually means the peak season when travel is most active during the Spring Festival in China annually. The translation "Spring Transportation" fails to manifest the connotation of the source word in Chinese cultural and may not be truly understood by the foreigners.

Therefore, mistranslation resulting from cultural ignorance is a problem that needs urgent attention and solution, or China will be regarded as a nation which is in the lack of cultural respect to other nations and at the same time these mistranslations may form a big impediment for other nations in the world to know Chinese culture better. 
Studies on translation from the cultural perspective break away from the traditional linguistically aimed and literarily oriented schools, and switch to a cultural orientation, which discovers a new way for translation studies and helps to build translation studies as an independent discipline.

\section{SUMMARY}

After a brief introduction of the functions and some common and frequent errors of the bilingual public signs in the city the author lives, the current situation of the translation of publicity in big cities in China shows up its deficiency. There is no denying that public signs play an important role in daily life, and their English versions contribute great help and convenience to the foreigners in China. Additionally, they also have become an effective way to set up China's international image. The current situation of English translation of these signs is not satisfactory, and various cases of poorly translated English signs present foreign readers with a jumbled meaning. Perhaps the greater problem is the abundance of Chinese-English signs used for directing foreign tourists to and from places. Although there are problems existing in the translation of bilingual public signs, it is still delightful to see that the issue has been bought to spotlight by the academic scene, government and even the general public, and it has already become a public concern which arouses a flaming public interest that it should have deserved for long.

\section{REFERENCES}

[1] Beizhu \& Shan Aimin. (2002). On Linguistic Features and the Translation of English Publicity. Academic Journal of Beijing Second Foreign Language School, 5, 76-79.

[2] Bian Zhengdong. (2005). On the Translation of Publicity. Shanghai Translation, 1, 27-31.

[3] Dai zongxian \& Lv Hefa. (2005). Research on Translation of Public Signs-Taking Sponsor City of Landon in the 2012 Olympic Games as An Example. China Translation, 6, 38-42.

[4] Dai zongxian \& Lv Hefa. (2006). Globalization and Standardization of Bilingual Graphic Symbol. Advertising, 6, 38-45.

[5] Jef Verschueren. (2000). Understanding Pragmatics. Beijing: Foreign Language Teaching and Research Press.

[6] Lv Hefa. (2004). Chinese-English Translation of Public Signs. China Technology Translation, 1,38-40.

[7] Nord Christiane. (2001). Translating as a Purposeful Activity. Shanghai: Shanghai Foreign Language Education Press.

[8] Wang Yin \& Lv Hefa. (2007). Translation of Public Signs. Beijing: China Foreign Translation Press Cooperation.

Minghe Guo, female, aged 33, graduated from the school of Foreign languages, Changchun University of Science and Technology, in June 2001. Since her graduation, she has been engaging in college English teaching in Changchun University of Science and Technology for eleven years. In 2007, she got Master of Arts degree in Foreign Language Linguistics and Applied Linguistics from Changchun University of Science and Technology. She all along has a keen interest in linguistics and college English education and research and pays close attention to the new trends and new challenges in English language learning and teaching field. In recent years, she completed and published more than ten papers on the issues of linguistics and college English education and participated in several subject research projects. 